\title{
Statistical selection of ASTER's VNIR, SWIR and TIR band ratio combinations for geological photointerpretation of Porongos Complex (RS, Brazil)
}

Gabriel da Silva Pontes ${ }^{* 1}$, Juliana Pertille da Silva ${ }^{1},{ }^{1}$ UFPel

\author{
Copyright 2021, SBGf - Sociedade Brasileira de Geofísica
}

This paper was prepared for presentation during the $17^{\text {th }}$ International Congress of the Brazilian Geophysical Society held in Rio de Janeiro, Brazil, 16-19 August 2021.

Contents of this paper were reviewed by the Technical Committee of the $17^{\text {th }}$ International Congress of the Brazilian Geophysical Society and do not necessarily represent any position of the SBGf, its officers or members. Electronic reproduction or storage of any part of this paper for commercial purposes without the written consent of the Brazilian Geophysical Society is prohibited.

\begin{abstract}
Aiming an optimized geological photointerpretation in terms of maximum availability of surficial mineral, soil and rock spectral information, nine, vegetation masked, ASTER BR images were calculated, with respect to the Porongos Complex (southernmost of Rio Grande do Sul state, Brazil). Those ratios were obtained utilizing VNIR, SWIR and TIR data. All the eighty-four possible threecomponent FCC were evaluated through the SI, which ranked those $\mathrm{BR}$ triplets from best to worst, regarding information availability, by assessing the determinant of the covariance matrix of each one of them. The false color composite $(4+5) / 6$ on the red component, $2 / 1$ on the green component and $12 / 13$ on the blue component, was the triplet ranked as the best, and was compared with the available geological information. Through the application of the described methodologies, the authors envision valuable qualitative geological information extraction related to the Porongos Complex in the studied region, as well as the possibility of further integration and validation with collateral data.
\end{abstract}

\section{Introduction}

False Color Composites (FCC) and Band Ratios (BR) are image processing techniques used as information extraction tools, since the beginning of the utilization of remote sensing in geological studies [e.g., Goetz et al, 1975; Sabins, 1999; Van der Meer et al, 2012; Gupta, 2018]. FCC is an alternative for chromatically displaying and synthesizing three different spectral information [i.e., channel triplets] (Crosta, 1992; Jensen, 2015). Furthermore, BR enhances subtle spectral features [e.g., mineral abundance and/or chemical composition], whilst suppressing albedo and terrane illumination effects (Goetz et al, 1975; Gupta, 2018).

It is recommended that both techniques (FCC and $B R$ ) account for the geological context. Hence, choosing a BR triplet for generating an optimized FCC, in which the available mineral, soil and rock surficial spectral information will be the highest, is significant for an optimized geological photointerpretation.

Beauchemin and Fung (2001) revised the main indexes for automating the process of choosing such optimized FCC, namely: the Optimum Index Factor (OIF) (Chavez et al., 1982) and the Sheffield Index (SI) (Sheffield, 1985). Based on the evaluation of the BR (or channel) statistics, those indexes attempt to validate the hypothesis of selecting a subset of BR triplets, in which spectral information is maximized, and data loss is negligible (Beauchemin and Fung, 2001). In this regard, SI ranks all available BR triplets with respect to the determinant of covariance matrix, rather than total variance, minimizing high pairwise correlation (Sheffield, 1985).

Thus, in this study, SI has been applied to obtain one optimized FCC. The original dataset corresponded to eighty-four BR triplets, generated from nine calculated BR, for one Advanced Spaceborne Thermal Emission and Reflection Radiometer (ASTER) subscene. Given that adjacent channels, regarding spectral information, are highly correlated, visible and near-infrared (VNIR), shortwave infrared (SWIR) and thermal infrared (TIR) data were used for BR calculations to increase spectral information diversity. Besides, due to the purpose of emphasizing surficial mineral, soil and rock spectral information, vegetation effect on scene statistics was suppressed [e.g., Chavez et al, 1982], by using a mask created with the Normalized Difference Vegetation Index (NDVI), commonly used to evaluate the vegetation vigor state due to its low degradation products (Rouse et al., 1974 apud Bannari et al., 1995). The previously described dataset was selected for the study area, which comprises the geological context of the south-central portion of Porongos Complex, southernmost of Rio Grande do Sul state, Brazil (figure 1). The aim of this study was to optimize FCC choosing, generation, and consequently, its photointerpration, to extract maximized and valuable qualitative geological information related to Porongos Complex.

\section{Method}

Processing routines were applied on a cloud free, Level 1 Precision Terrain Corrected Registered At-Sensor Radiance ASTER scene, with activated SWIR mode.

A summary of those routines, which are further described, encompass: I) pre-processing and subscene definition; II) NDVI calculation; III) utilization of NDVI as a proxy for vegetation cover estimates and creation of a vegetation mask; IV) calculation of the nine BR images; V) application of the mask on the calculated BRs for suppressing the statistical effect of vegetation; VI) SI calculation utilizing all the eighty-four possible BR triplets combination; VII) ranking of the optimized BR triplets; and VIII) FCC generation and photointerpretation. 


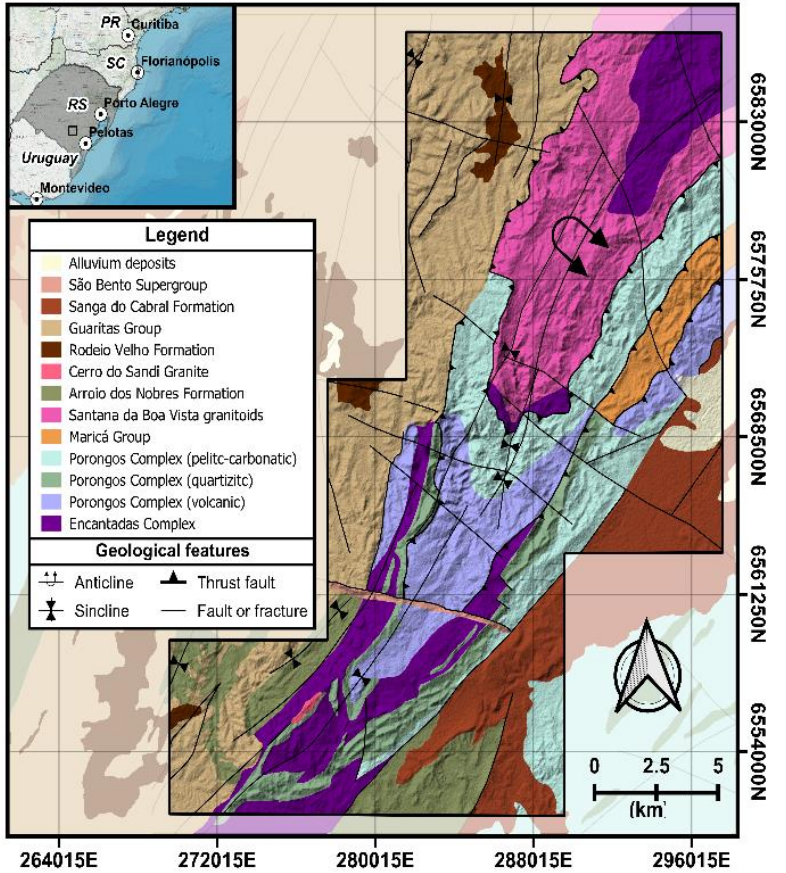

Figure 1: Location and geological map of the study area (Adapted from Takehara and Laux, 2019).

Pre-processing was incorporated as a preparatory step to account for inherently degradation in raw data (Jensen, 2015; Gupta, 2018). All ASTER channels were geometric and radiometrically corrected: co-registering, reprojection, spatial resolution resampling to $15 \mathrm{~m}$ through Nearest Neighbor algorithm [i.e., for SWIR and TIR] and subscene definition, stands for the first correction type, while radiometric calibration from Digital Numbers to Registered At-Sensor Radiance (Abrams and Yamaguchi, 1999) accounts for the latter. Top of Atmosphere Reflectance (from Landsat 7 Users Handbook) data was also obtained from first order VNIR and SWIR calibrated data. To account for the path radiance and scattering effects of the atmosphere, the image-based method Dark Object Subtraction (Chavez, 1988; Chavez, 1996) was carried out on VNIR and SWIR channels for obtaining surface pseudoreflectance data. TIR data was not atmospherically corrected following Ninomiya and Fu (2019).

The corrected VNIR data was used to calculate NDVI, as follows:

$$
N D V I=\frac{(N I R-R e d)}{(N I R+R e d)} \rightarrow N D V I_{A S T E R}=\frac{(3 N-2)}{(3 N+2)}
$$

The generated NDVI image of this study (figure 2), yields 0.7821 to 0.8121 range of surface pseudo-reflectance values. This range was utilized as a proxy for estimating vegetation cover in the area. The aforementioned was accomplished by defining a threshold value in which values equal to, or higher than it, were to be treated as vegetation information. The value of 0.5451 was the estimated threshold and it was utilized for creating a mask for vegetation picture elements.

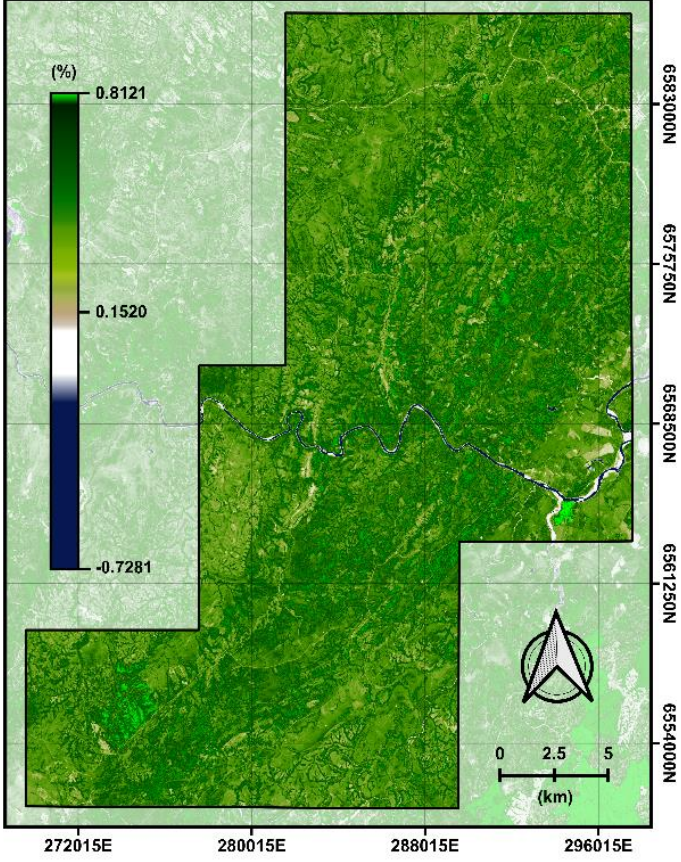

Figure 2: NDVI calculated for the described dataset.

BR calculations were made accounting for Porongos Complex geological context on the studied area. Locally, it can be defined by its regional structural emplacement, named Godinho's Antiform, that records the following lithological associations: orthogneiss, mylonitic granites, phyllites, pelitic schists, quartzites, quartz mylonites, graphite schists, marble lenses and metavolcanic rocks, which register greenschist facies to medium amphibolite facies (Jost and Bitencourt, 1980; Porcher and Fernandes, 1990; Porcher and Lopes, 2000; Saalman et al., 2006, Takehara and Laux, 2019). Volcano-sedimentary sequences related to Camaquã and Paraná Basin are also mappable on the studied area (Takehara and Laux, 2019).

Given this framework, the calculated BR to enhance mineral, soil and rock surface spectral information, were: I) $2 / 1$, an index for ferrous iron; II) $5 / 4$, an index for iron silicates; III) $(4+5) / 6$, an index for clay minerals such as alunite, kaolinite and/or pyrophyllite; IV) $(5+7) / 6$, an index for white micas such as sericite, muscovite, ilite and/or smectite; V) 7/6, a generalized index for micas; VI) 6/8, a indexes for amphibole mineral group; VII) (11X11)/(12X10) a siliceous rocks index; VIII) 12/13, a indexes for mafic rocks and minerals (as well as an inverse felsic rocks and minerals index); and IX) 14/12, an index for quartz-rich rocks [e.g., Cudahy and Hewson, 2002; Van der Meer et al., 2012; Pour and Hashim, 2014; Gupta, 2018; Ninomiya and $\mathrm{Fu}, 2019]$.

Prior to SI calculation, unnecessary standard deviation related to vegetation cover was suppressed from each one of the nine calculated BR, by the mapped vegetation picture elements on the mask (figure 3 ). 


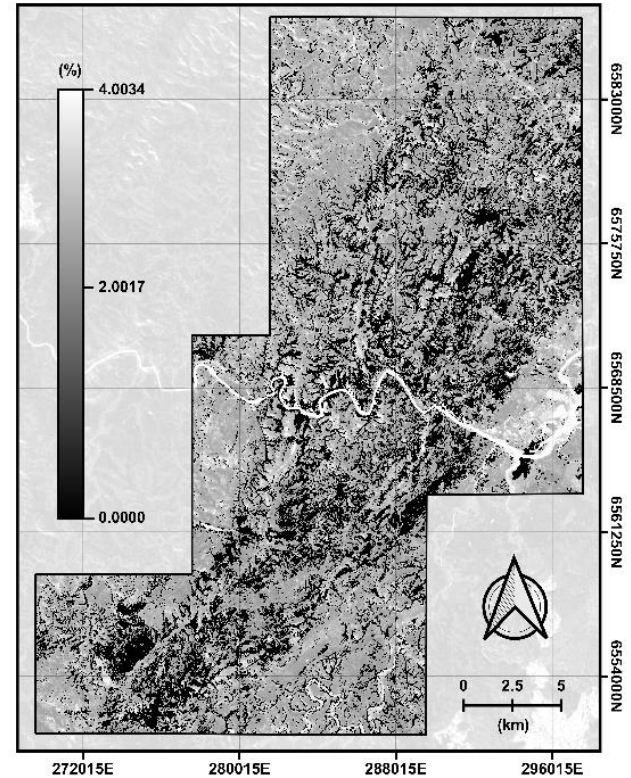

Figure 3: Example map of vegetation masked BR (5/4).

SI was then calculated, through the assessment of the eighty-four possible BR triplets covariance matrix determinant, followed by its ranking from highest to lowest magnitudes. SI was calculated as follows:

$$
S I=\operatorname{det}\left[\frac{1}{n-1} \sum_{i=1}^{n}\left(X_{i}-\bar{X}\right) \cdot\left(X_{i}-\bar{X}\right)^{T}\right] \mid X \in R^{3 \times 3}
$$

where $X$ is the matrix of the BR triplets, $\bar{X}$ is the matrix of the mean of the BR triplets and $n=4,973,492$ [i.e., the number of samples for each BR].

FCC generation can be mathematically expressed as a linear combination of red $(R)$, green $(G)$ and blue $(B)$ colors and the mixture coefficients $r, g$ and b (Crosta, 1992; Jensen, 2015). Thus:

$$
F C C=(r \cdot R)+(g \cdot G)+(b \cdot B)
$$

Even though SI elects the best BR triplet as for the evaluated context, in order to generate the optimized FCC, it is still necessary to relate the color component with the ratio image that will exhibit this color in its best manner. Thus, one can associate specific colors with total variance of BR. Synoptically, total variance can be related to colors as follows: generally, on an FCC, green color can be better distinguished by the human eye when it is attributed to the highest total variance component, whereas red and blue color are more easily perceived when attributed to the second highest and the lowest total variance components, respectively (Sheffield, 1985; Crosta, 1992; Jensen, 2015).

\section{Results and discussions}

The main results relate to the calculation of SI. This calculation, performed to all of the eighty-four BR triplets, was ranked regarding maximization of mineral, soil and rock surficial spectral information (Table 1). From this ranking, one of the eighty-four BR triplets was elected as the best one in terms of maximum spectral information of interest: the $12 / 13,2 / 1,(4+5) / 6$ ratio images triplet.

For generating the optimized FCC, total variance regarding each BR was considered. On a covariance matrix, the total variance of its components corresponds to the main diagonal. With reference to the highest ranked BR triplet, such matrix, and consequently, the total variance of its components, is presented in table 2 .

Table 1: Summarized SI values and ranked BR triplets.

\begin{tabular}{|l|c|c|}
\hline Classification & SI & BR triplets \\
\hline 1 & 504,798 & $12 / 13 ; 2 / 1 ;(4+5) / 6$ \\
\hline 2 & 439,707 & $2 / 1 ;(4+5) / 6 ;(5+7) / 6$ \\
\hline 3 & 361,406 & $2 / 1,(4+5) / 6,7 / 6$ \\
\hline 4 & 244,993 & $12 / 13 ; 2 / 1 ;(5+7) / 6$ \\
\hline 5 & 234,041 & $2 / 1 ;(4+5) / 6 ; 6 / 8$ \\
\hline$\ldots$ & $\ldots$ & $\ldots$ \\
\hline 84 & 67 & $(11 \times 11 / 10 \times 12) ; 14 / 12 ; 5 / 4$ \\
\hline
\end{tabular}

Accordingly, the FCC $(4+5) / 6$ on red, $2 / 1$ on green and $12 / 13$ was generated as a cartographic product that synthesized the previous steps (Figure 4). The vegetation mask was applied only on SI calculation to suppress vegetation effect on image statistics, hence only unmasked BR were used for the FCC generation.

The highest ranked FCC is in accordance with the expected increase in spectral information, whenever extreme spectral domain components are colorfully combined. The best ranked FCC is also the one with highest individual variance, or diversity on spectral information of interest, due to the characteristics of the SI itself and vegetation information suppression.

The FCC map was photointerpreted to evaluate the reliability of a qualitative geological information extraction. This first order interpretation stressed reliable results (figure 5).

Table 2: Lower triangular covariance matrix for the best ranked $B R$ triplet.

\begin{tabular}{|l|c|c|c|}
\hline Ratios & $\mathbf{1 2 / 1 3}$ & $\mathbf{2 / 1}$ & $\mathbf{( 4 + 5 ) / 6}$ \\
\hline $\mathbf{1 2 / 1 3}$ & 417.859 & - & - \\
\hline $\mathbf{2} / \mathbf{1}$ & 677.652 & 1153.58 & - \\
\hline $\mathbf{( 4 + 5 ) / 6}$ & 527.922 & 875.127 & 695.687 \\
\hline
\end{tabular}




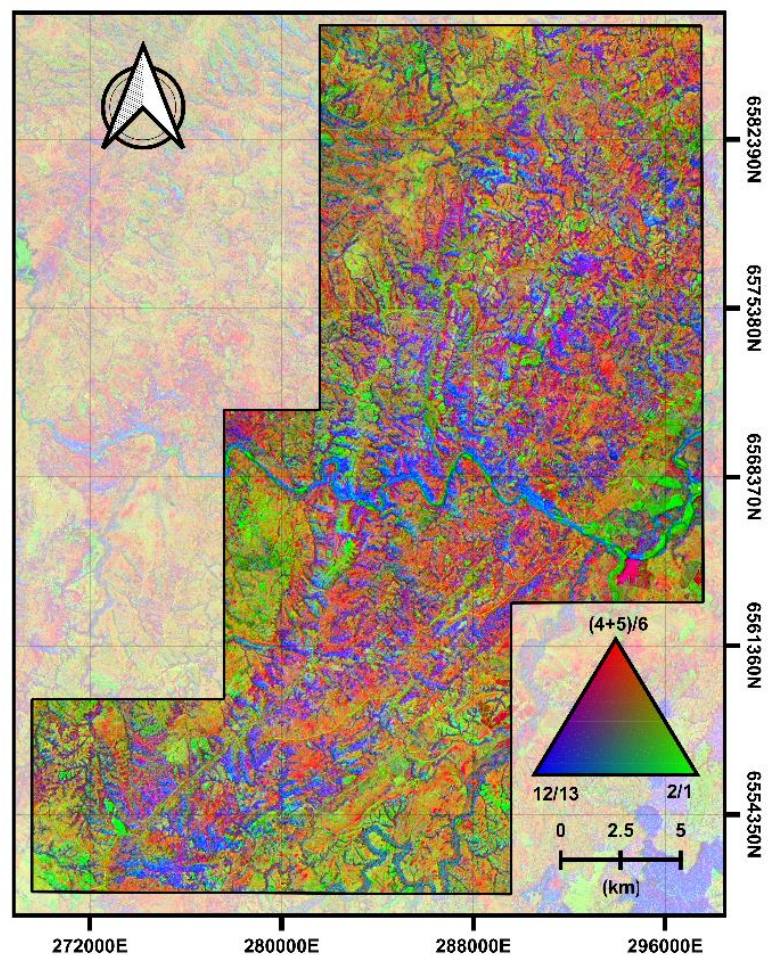

Figure 4: FCC map obtained from highest ranked SI, BR triplet.

Surficial spectral information agrees with the regional positioning of the main lithological units on the studied region. For instance, areas corresponding to mapped Porongos Complex units, seem to follow a NE-SW to ENEWSW structural pattern, which is in accordance with main its main orientation. This trend is somewhat accompanied by high to medium frequency, as well as low amplitude spectral patterns. Both of them are most intensively registered in the center and south-center regions of the studied area. Those frequency patterns represent also chromatically distinguishable patterns too, such as: highly saturated green areas; blue to purple areas; and orange yellow to brownish, yellow-colored areas. When related to the main regional geological data for the studied area, the structural orientation, frequency, amplitude and color patterns previously described, can be correlated with Porongos Complex units spatial distribution [e.g., Ramgrab and Wildner, 1999; Porcher and Lopes, 2000; Takehara \& Laux]. Regarding the color mixture patterns registered, vegetation contribution for the spectral data. This relationship, between with color mixture patterns and surficial composition can be further exploited with collateral data. Finally, high amplitude and low frequency features were predominantly recorded, on the edges.

\section{Conclusions}

The main conclusions regarding SI statistically electing the one BR triplet that accounted for the highest information (and negligible pairwise correlation) from eighty-four

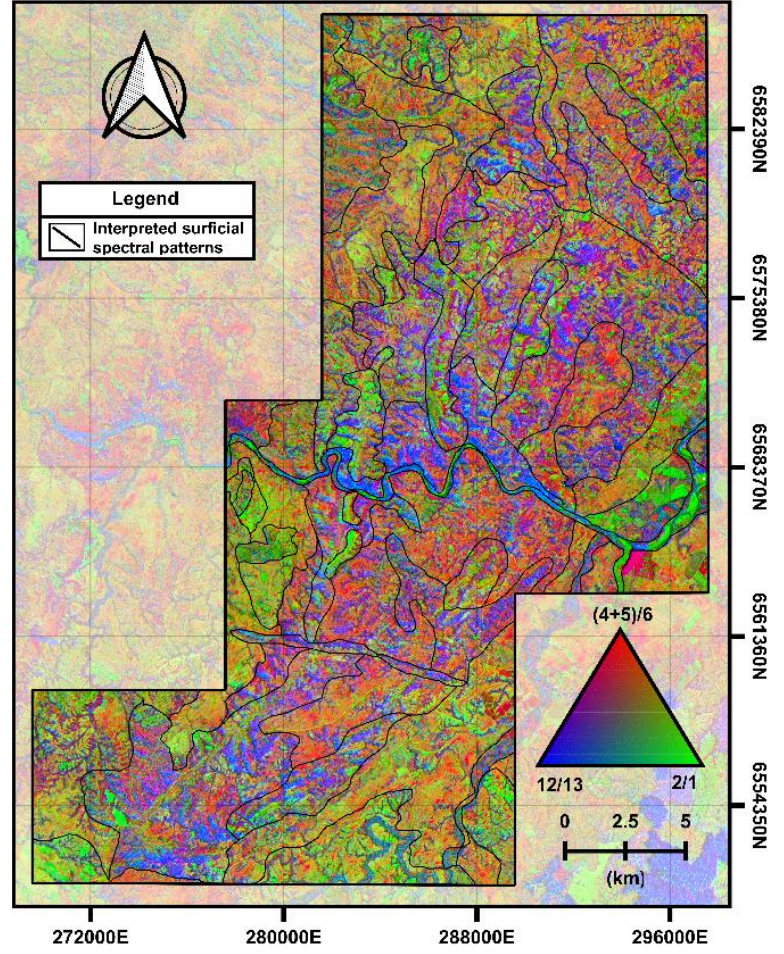

Figure 5: Preliminary interpreted map surficial spectral patterns of generated FCC.

available, exhibits good applicability with respect to the applied context. Hence, reliable information extraction regarding Porongos Complex on the studied area was accomplished. The possibility of integration and validation with collateral data is also subject of interest for further studies. In addition, this methodology can be applied in larger datasets [e.g., higher number of ratios or even a Hyperion hyperspectral sensor dataset with 220 channels], Thus, its utilization advised as an important optimization tool for speeding FCC generations with respect to the maximization of geological information. Consequently, photointerpretation could be optimized.

\section{Acknowledgments}

The authors acknowledge the Brazilian National Council for Scientific and Technological Development (CNPq) for its granted financial support (Edital Universal-2018, number: 436073/2018-8). The first author would also like to acknowledge CNPq for its granted scientific initiation scholarship. Both authors acknowledge the Geological Survey of Brazil for its free of charge databases and EarthExplorer of the United States Geological Survey (USGS) and Eearthdata National Aeronautics and Space Administration (NASA) for its free of charge ASTER data availability. 


\section{References}

ABRAMS, M. YAMAGUCHI, Y. 2002. ASTER User Handbook. Pasadena, California. Jet Propulsion Laboratory/California Institute of Technology.

BANNARI A. et al. 1995. A review of vegetation indices. Remote Sensing Reviews. 13. p. 95-120.

BEAUCHEMIN, M.; FUNG, K. B. On Statistical Band Selection for Image Visualization. 2001. Photogrammetric Engineering \& Remote Sensing, 67, p. 571-574.

CHAVEZ, P. S. et al. 1982. Statistical Method for Selecting Landsat MSS Ratios. Journal of Applied Photographic Engineering, 8, p. 23-30.

CHAVEZ, P. S. 1988. An improved dark-object subtraction technique for atmospheric scattering correction of multispectral data. Remote Sensing of Environment, 24, 459-479.

CHAVEZ, P. S. 1996. Image-Based Atmospheric Corrections: Revisited and Improved. Photogrammetric Engineering and Remote Sensing, 62, p. 1025-1036.

CUDAHY, T.; HEWSON, R. 2002. ASTER geological case histories: porphyry-skarn epithermal iron oxide $\mathrm{Cu}-\mathrm{Au}$ and Broken hill Pb-Zn-Ag. In: Annual General Meeting of the Geological Remote Sensing Group 'ASTER Unveiled', Burlington House, Piccadilly, London, UK.

GOETZ, A. F. H. et al. Application of ERTS Images and Image Processing to Regional Geological Problems and Geological Problems in Northern Arizona. U.S. National Aeronautics and Space Administration, Jet Propulsion Laboratory, Technical Report, 321597, 188pp, 1975.

HARTMANN, L. A.; PORCHER C. C.; REMUS, M.V. D. 2000. Evolução das Rochas Metamórficas do Rio Grande do Sul. In: HOLZ, M.; DE ROS, L. F. (Ed.). Geologia do Rio Grande do Sul: CIGO/UFRGS, 79-118.

HARTMANN, L. A.; CHEMALE JUNIOR., F.; PHILLIP, R. P. 2007. Evolução Geotectônica do Rio Grande do Sul no Pré Cambriano. In: IANNUZZI, R.; FRANTZ, J. C. (Ed.). 50 anos de Geologia: Instituto de Geociências, contribuições: Comunicação e Identidade, 96-123.

GUPTA, R. P. Remote Sensing Geology. Berlin: SpringerVerlag Berlin Heidelberg, 2018.

JENSEN, J. R. Introductory digital image processing: a remote sensing perspective. Pearson Education, 2015.

JOST, H.; BITENCOURT, M. 1980. Estratigrafia e tectônica de uma fração da faixa de dobramentos Tijucas no Rio Grande do Sul. Acta Geologica Leopoldensia, 11, p.27-59.
NASA., 2009. Landsat 7 Science Data Users Handbook. USA: NASA.

NINOMIYA, Y.; FU, B. 2019. Thermal infrared multispectral remote sensing of lithology and mineralogy based on spectral properties of materials. Ore Geology Reviews, 108 , p. 54-72.

PERTILLE, J. et al. 2017. Reconstructing the Cryogenian Ediacaran evolution of the Porongos fold and thrust belt, Southern Brasiliano Orogen, based on Zircon U-Pb-Hf-O isotopes. International Geology Review, 59, p.1-29.

PORCHER, C. C.; FERNANDES, L. 1990. Relações embasamento/"cobertura" na porção ocidental do Cinturão Dom Feliciano: um esboço estrutural. Pesquisas em Geociências, 17, p. 72-84.

PORCHER, C. A.; LOPES R. C. 2000. Cachoeira do Sul, folha SH.22-Y-A: estado do Rio Grande do Sul. Brasília: CPRM.

POUR, B.; HASHIM, M. 2014. ASTER, ALI and Hyperion sensors data for lithological mapping and ore minerals exploration. SpringerPlus, 3, p. 130-149.

RAMGRAB, G. E.; WILDNER, W. 1999. Pedro Osório, Folha SH.22-Y-C: Estado do Rio Grande do Sul. Brasília: CPRM.

SABINS, F.F. 1999. Remote Sensing for Mineral Exploration. Ore Geology Reviews, 14, 157-183.

SAALMANN, K., REMUS, M.V.D.; HARTAMNN, L. A. 2006. Structural evolution and tectonic setting of the Porongos belt, southern Brazil. Geology Magazine, 143, p.59-68.

TAKEHARA, L.; LAUX, J. H. 2019. Área de relevante interesse mineral: Batólito Pelotas-Terrenos Tijucas: estado do Rio Grande do Sul. Porto Alegre: CPRM,

VAN DER MEER, F. et al. 2012. Multi-and hyperspectral geologic remote sensing: A review. International Journal of Applied Earth Observation and Geoinformation, v.14, p. 112-128. 